\title{
Do morphology and stage explain the inferior lung cancer survival in Denmark?
}

\author{
H.H. Storm*, P.W. Dickman*, A. Engeland ${ }^{\S}$, T. Haldorsen $^{+}$, T. Hakulinen ${ }^{\#}$
}

\begin{abstract}
Do morphology and stage explain the inferior lung cancer survival in Denmark? H.H. Storm, P.W. Dickman, A. Engeland, T. Haldorsen, T. Hakulinen. (C) ERS Journals Ltd 1999. ABSTRACT: Danish lung cancer patients diagnosed during 1983-1987 experienced 5 -yr relative survival rates $2-7 \%$ inferior to patients in the other Nordic countries, despite the similarity of cancer registration and healthcare systems in the Nordic countries. Is the inferior relative survival in Denmark due to differences in morphology or stage of lung cancers?

The present study compared in detail the survival of 92,719 patients diagnosed with lung cancer during 1978-1992 in Denmark, Finland, and Norway. In particular, differences in morphology and extent of disease were studied.

A poor survival rate for small cell anaplastic lung carcinoma compared with all other morphologies was confirmed. However, this could not explain the relative survival differences observed between countries. Extent of disease was the most important predictor of survival. Part of the observed survival differences could be explained by a less favourable stage distribution in Denmark, combined with a slightly lower relative survival rate for those with metastatic disease. Differences in treatment are unlikely to explain the findings, although delays in diagnosing and treating patients in Denmark compared with neighbouring countries could partially explain the lower patient survival in Denmark.
\end{abstract}

In conclusion, the main factor in the lower survival rate in Denmark is unfavourable stage distribution.

Eur Respir J 1999; 13: 430-435.
*Institute of Cancer Epidemiology, Danish Cancer Society, Copenhagen Denmark; Dept of Statistics, University of Newcastle, NSW, Australia; ${ }^{5}$ National Institute of Public Health, Dept of Population Health Sciences; ${ }^{+}$The Cancer Registry of Norway, Oslo, Norway; and "Finnish Cancer Registry, Helsinki and Dept of Public Health, University of Helsinki, Finland.

Correspondence: H.H Storm, Institute of Cancer Epidemiology, Danish Cancer Society, Copenhagen, Denmark, Fax: 45 35257731

Keywords: Cancer registries, epidemiology, lung, morphology, stage, survival

Received: March 181998

Accepted after revision October 91998

The Nordic Cancer Union (NCU) provided the financial support for the projects.
Survival after lung cancer is in general poor, with $<10 \%$ of patients surviving $5 \mathrm{yrs}$ after diagnosis $[1,2]$. Stage of disease and morphological type are known predictors of survival, with small cell anaplastic carcinomas and nonlocalized cases (the most common presentation of this cancer) experiencing the least favourable survival [3]. Only marginal improvement has been observed following the introduction of systemic treatment, improvement in radiotherapy, surgical, and diagnostic techniques. It has long been known that the aetiology of almost all lung cancers is tobacco smoking [4], and thus prevention through control of tobacco smoking should be given the highest priority in order to lower the incidence of, and thus the mortality from, this disease. Male lung cancer incidence in Denmark was 58.3 cases per 100,000 person-yrs during 1983-1987 (age-adjusted to the world standard population) and in females 23.0 cases per 100,000 [5]. These rates were among the highest in the Nordic countries, probably due to the high prevalence of tobacco smoking in Denmark. Early detection of the disease by chest radiography screening of healthy individuals without symptoms is often suggested, but so far all screening trials have been consistent in showing no beneficial effect [6, 7], although a long-term effect cannot be ruled out [8]. The authors are not aware of any previous or ongoing early detection activity in the Nordic countries, which could affect the stage distribution and incidence of lung cancer. Irrespective of the higher incidence, survival would be expected to be similar in Denmark to the other Nordic countries.

The joint analysis of survival in Europe [2] compared 5yr relative survival to that of the general population and found overall survival following lung cancer in Denmark, Scotland, and England to be $40-50 \%$ lower than the relative survival seen in Switzerland, the Netherlands, and Finland. But biases such as heterogeneity in registration methods could not be ruled out as explanations for the findings. A recently published prediction of cancer mortality in the Nordic countries [1] showed a 5-yr relative survival disadvantage of $2-7 \%$ for Danish lung cancer patients in the period 1983-1987 compared with the other Nordic populations, a difference which was not present in 1958-1962 (figs. 1 and 2). Although the prognosis for lung cancer patients is still poor, all Nordic countries except Denmark have experienced improvements in survival since 1958. This finding was surprising owing to the homogeneity of both registration and healthcare in the Nordic countries.

The aim of the present study was to analyse patient survival in more detail, in an attempt to explain the lower patient survival in Denmark. In particular, the differences in stage and/or morphology of small cell anaplastic carcinoma were studied to determine whether or not they contributed to the lower patient survival in Denmark. 


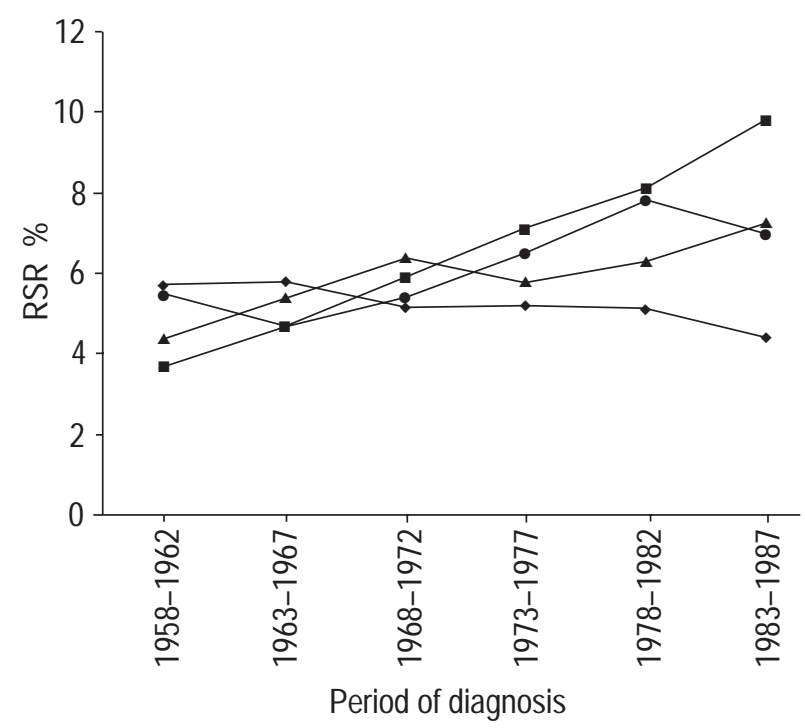

Fig. 1. - Relative 5-yr lung cancer survival in the Nordic countries for males, 1958-1987. $\bullet$ : Denmark; $\mathbf{\square}$; Finland; $\mathbf{\Delta}$ : Norway; $\bullet$ : Sweden. RSR: relative survival rate. (Adapted from [1].)

\section{Materials and methods}

Notification of cancer is compulsory in the Nordic countries and the cancer registration data are known to be of both high validity and completeness $[1,9]$. All countries run fairly similar nationwide, population-based cancer registration systems, and all use the national, unique personal identification number for linkages. As such, neither a cancer nor a death among cancer patients is likely to be missed. All countries included in this analysis use death certificates in the registration process, and perform follow-back of cases first identified in this way.

The case-specific data used for the prediction of Nordic cancer incidence and mortality $[1,5,10]$ were also used for the present study, since these data had previously been carefully examined and adapted to a common format

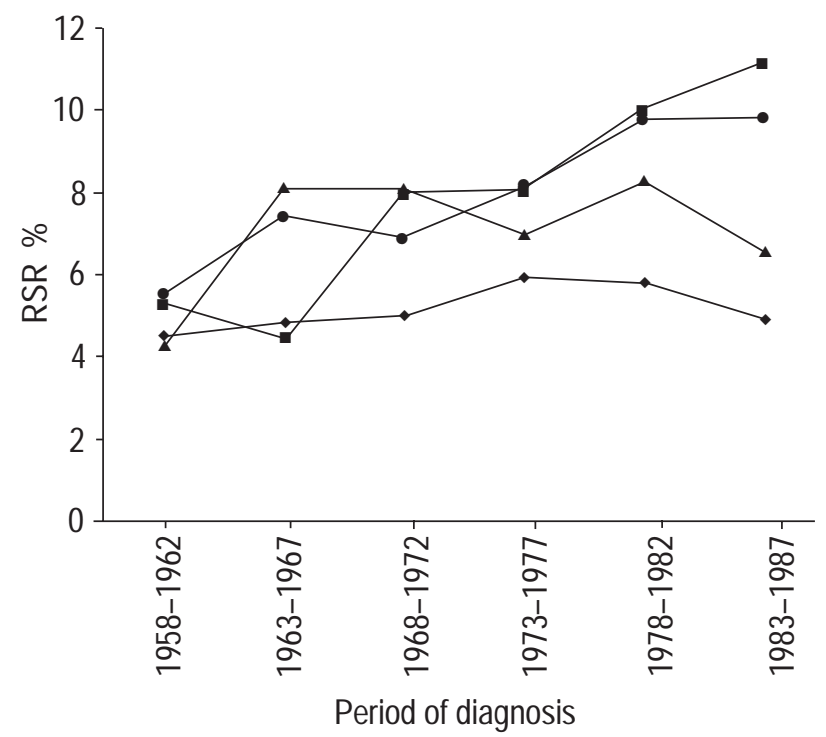

Fig. 2. - Relative 5-yr lung cancer survival in the Nordic countries for females, 1958-1987. $\bullet$ : Denmark; घ; Finland; $\mathbf{\Delta}$ : Norway; $\bullet$ : Sweden. RSR: relative survival rate. (Adapted from [1].) (table 1). Data from Sweden did not contain information on stage and were excluded from the analysis, as were data from Iceland, which were too sparse to facilitate the planned analysis of patient survival.

Details of morphology were required, and the period from 1978 onwards was selected, where morphology was available from Denmark coded according to the International Classification of Disease for Oncology (ICD-O) [11], from Norway according to Manual of Tumor Nomenclature and Coding (MOTNAC)-1968 [12], and from Finland according to MOTNAC-1958 [12]. This allowed classification into small cell carcinoma, large cell carcinoma, squamous cell carcinoma, and adenocarcinoma, with all other histologically verified cases grouped together and called "others" (table 2). Cases registered without histological verification were also analysed as a separate group, called "missing". In Finland, however, there is no specific code for large cell carcinoma, and the group labelled large cell carcinoma also includes cases with other morphologies. When analysing patient survival, small cell carcinoma and squamous cell carcinoma were analysed as separate groups, and all other histologically verified cases were grouped into the "others" group. Patient survival was also estimated for those cases without histological verification. Clinical stage of disease was available is detail, allowing discrimination between localized and nonlocalized cases and those with unknown spread.

The same data and the same exclusion criteria were used as in previous analysis [10]. In brief, all incident cases except those known only from death certificates, those diagnosed at autopsy, and those $\geq 90$ yrs at diagnosis were included for the period 1978-1991 for Denmark and 1978-1992 for Finland and Norway. Patients were followed-up for deaths through to 1991 in Denmark, to 1992 in Norway, and to 1993 in Finland.

Relative survival rates $[13,14]$ were estimated using software developed at the Finnish Cancer Registry [15]. In order to estimate relative survival, general (all-cause) mortality rates were obtained from the central statistical office of each country. Survival was estimated for annual followup intervals, although the results are presented here in terms of 5-yr relative survival rates only.

In order to compare these results to those recently published in the European Cancer Survival and Care (EUROCARE) study [2], the European Cancer Incidence and Mortality (EUROCIM) database [16] was used to study the morphology distribution of lung cancer in other European registries.

\section{Results}

In total, 92,719 patients were included in the Nordic analysis (table 1). A higher proportion of nonlocalized cases (and a correspondingly lower proportion of localized cases) was seen in Denmark. The number of cases with unknown stage was very low in Norway, high in Finland and medium-high in Denmark. The percentage of cases with unknown stage is lower in Norway, partly because the Norwegian Cancer Registry routinely receives all pathology reports, which include some staging information.

The distribution of the number of cases by morphological type is presented in table 2 . However, differences in morphology coding practices between the three registries 
Table 1. - Lung cancer cases diagnosed 1978-1991 or 1992 by country and stage for both sexes

\begin{tabular}{|c|c|c|c|c|c|c|c|c|}
\hline & \multicolumn{2}{|c|}{ Localized } & \multicolumn{2}{|c|}{ Nonlocalized } & \multicolumn{2}{|c|}{ Unknown stage } & \multicolumn{2}{|c|}{ Total } \\
\hline & $\mathrm{n}$ & $\%$ & $\mathrm{n}$ & $\%$ & $\mathrm{n}$ & $\%$ & $\mathrm{n}$ & $\%$ \\
\hline Finland & 8222 & 25.8 & 17130 & 53.9 & 6455 & 20.3 & 31807 & 100 \\
\hline Denmark & 8783 & 21.9 & 25520 & 63.5 & 5861 & 14.6 & 40164 & 100 \\
\hline Norway & 6749 & 32.5 & 13056 & 62.9 & 943 & 4.5 & 20748 & 100 \\
\hline Total & 23754 & 25.6 & 55706 & 60.1 & 13259 & 14.3 & 82719 & 100 \\
\hline
\end{tabular}

complicate comparisons. Small cell, squamous cell, and adenocarcinomas can be identified in the Finnish material, but the large cell carcinoma category, as mentioned in the materials and methods section, also includes other carcinoma types. Hence, the percentage of large cell carcinomas is artificially higher in Finland than in the other countries. The Finnish Cancer Registry also uses separate codes for cases where histology has been recorded, but the registry has received either conflicting information or no information. Of the 8,790 Finnish cases classified as "missing" (morphology not available), 46 and 302 fell into these categories, respectively.

Squamous cell carcinomas are the predominating cell type and can be identified in each of the three registries. The percentage of squamous cell carcinomas is similar for each of the three countries. The distribution of morphology is similar in Denmark and Norway, except for a lower number of large cell carcinomas in Norway. The distribution is slightly different in Finland, probably owing to the differences in coding practices mentioned previously.

Five-yr relative survival rates were highest among the young $(<65 \mathrm{yrs})$, and if the lung cancer was reported as localized (table 3 ). Survival was similar for localized cases in Norway and Denmark in each of the three age strata, whereas the relative survival was superior in all categories of localized disease in Finland. When looking at the patients with stage reported as nonlocalized (the group accounting for $>50 \%$ of cases), Danish relative survival rates are consistently lower than the Norwegian and Finnish rates. The survival pattern for cases reported with unknown stage also shows a less favourable relative survival in Denmark compared with Finland, whereas this category is almost nonexistent in Norway, where most cases have stage reported.

Taking morphology into account, the survival pattern with respect to age and stage of disease is repeated, however, relative survival is clearly inferior for small cell carcinoma compared with nonsmall cell carcinoma. Interestingly, those lung cancers where histology was not reported seem to behave similarly to, or a little worse than, small cell carcinoma (table 4).

\section{Discussion}

Five-yr relative survival rates following a diagnosis of lung cancer were studied in three Nordic countries by morphology and stage. The aim was to establish whether the distribution of lung cancer types could explain the previously observed poor survival in Denmark, or if differences in stage-specific survival were present.

In agreement with previous published studies [3, 1719], a less favourable 5-yr survival for small cell lung cancer was found. If a higher proportion of such cases was observed in countries with poorer patient survival, then this would (at least partially) explain the observed survival differences. The proportion of small cell carcinoma in the Nordic countries was, however, rather similar within the countries, with $19 \%$ in Norway and Denmark and $15 \%$ in Finland, and the survival experience for this type of lung cancer did not differ dramatically. Also, data from the EUROCIM 1995 database [16] for those registries represented in the EUROCARE analysis [2] do not support this hypothesis. Registries with a high proportion of small cell lung carcinoma, such as Switzerland $(20 \%)$ and the Netherlands (15\%), are found among those with a better relative survival rate (11-12\%), and registries with a low proportion of small cell lung carcinoma (England and Italy, 10\%), among those with a poor survival (relative survival rate $\sim 6 \%$ ). With respect to stage-specific survival, it is clear that Finnish males and females have a better relative survival than both their Norwegian and Danish counterparts, although the survival differences for localized small cell carcinomas among females are negligible. For

Table 2. - Morphology of lung cancer cases diagnosed 1978-1991 or 1992 by country for both sexes

\begin{tabular}{|c|c|c|c|c|c|c|c|}
\hline \multirow[b]{2}{*}{ Morphology } & \multicolumn{2}{|c|}{ Finland } & \multicolumn{2}{|c|}{ Denmark } & \multicolumn{2}{|c|}{ Norway } & \multirow{2}{*}{$\begin{array}{c}\text { Total } \\
\mathrm{n}\end{array}$} \\
\hline & $\mathrm{n}$ & $\%$ & $\mathrm{n}$ & $\%$ & $\mathrm{n}$ & $\%$ & \\
\hline Small cell & 4910 & 15.4 & 7454 & 18.6 & 3978 & 19.2 & 15579 \\
\hline Large cell ${ }^{*}$ & 3411 & 10.7 & 3221 & 8.0 & 750 & 3.6 & 7382 \\
\hline Squamous & 9962 & 31.3 & 12160 & 30.3 & 6244 & 30.1 & 28366 \\
\hline Adenocarcinoma & 4514 & 14.2 & 8312 & 20.7 & 4579 & 22.1 & 17405 \\
\hline Missing ${ }^{\#}$ & 8790 & 27.6 & 4318 & 10.8 & 2565 & 12.4 & 15673 \\
\hline Other & 220 & 0.7 & 4699 & 11.7 & 2632 & 12.7 & 8314 \\
\hline Total & 31807 & 100 & 40164 & 100 & 20748 & 100 & 92719 \\
\hline
\end{tabular}

$\ddagger$ : includes other carcinomas in Finland; ${ }^{\#}$ : includes cases where a history sample was not taken, except for Finland, where the figure also includes 302 cases where a histological diagnosis was made, but it is unknown to the registry, and 46 cases where the histological diagnosis was conflicting or unclear. 
Table 3. - Number of cases and 5-yr relative survival rates (RSR) by age, sex and stage in three Nordic countries, cases diagnosed 1978-1991 or 1992

\begin{tabular}{|c|c|c|c|c|c|c|}
\hline \multirow[b]{2}{*}{ Age } & \multicolumn{2}{|c|}{ Finland } & \multicolumn{2}{|c|}{ Denmark } & \multicolumn{2}{|c|}{ Norway } \\
\hline & $\mathrm{n}$ & RSR & $\mathrm{n}$ & RSR & $\mathrm{n}$ & RSR \\
\hline \multicolumn{7}{|l|}{ Males } \\
\hline \multicolumn{7}{|l|}{$<65$ yrs } \\
\hline Nonlocalized & 6472 & 0.04 & 7039 & 0.03 & 4055 & 0.05 \\
\hline Unknown & 1576 & 0.14 & 1015 & 0.11 & 143 & 0.03 \\
\hline \multicolumn{7}{|l|}{$65-69$ yrs } \\
\hline Localized & 1533 & 0.26 & 1365 & 0.20 & 1053 & 0.18 \\
\hline Nonlocalized & 2899 & 0.03 & 3674 & 0.02 & 2163 & 0.04 \\
\hline Unknown & 1034 & 0.08 & 731 & 0.06 & 102 & 0.05 \\
\hline \multicolumn{7}{|l|}{$>70 \mathrm{yrs}$} \\
\hline Localized & 2822 & 0.13 & 2904 & 0.10 & 2728 & 0.09 \\
\hline Nonlocalized & 4994 & 0.01 & 7038 & 0.01 & 3519 & 0.02 \\
\hline Unknown & 2933 & 0.05 & 2413 & 0.03 & 456 & 0.03 \\
\hline \multicolumn{7}{|l|}{ All ages } \\
\hline Localized & 7108 & 0.25 & 6412 & 0.19 & 5263 & 0.19 \\
\hline Nonlocalized & 14365 & 0.03 & 17751 & 0.02 & 9737 & 0.04 \\
\hline Unknown & 5543 & 0.09 & 4159 & 0.07 & 701 & 0.03 \\
\hline \multicolumn{7}{|l|}{ Females } \\
\hline \multicolumn{7}{|l|}{$<65$ yrs } \\
\hline Localized & 460 & 0.50 & 1130 & 0.32 & 508 & 0.29 \\
\hline Nonlocalized & 1106 & 0.06 & 3867 & 0.03 & 1550 & 0.05 \\
\hline Unknown & 226 & 0.23 & 559 & 0.06 & 57 & 0.10 \\
\hline \multicolumn{7}{|l|}{$65-69$ yrs } \\
\hline Localized & 214 & 0.32 & 434 & 0.25 & 270 & 0.25 \\
\hline Nonlocalized & 489 & 0.04 & 1403 & 0.02 & 604 & 0.05 \\
\hline Unknown & 139 & 0.11 & 289 & 0.05 & 34 & 0.13 \\
\hline \multicolumn{7}{|l|}{$>70$ yrs } \\
\hline Localized & 440 & 0.19 & 807 & 0.10 & 708 & 0.11 \\
\hline Nonlocalized & 1170 & 0.02 & 2499 & 0.01 & 1165 & 0.03 \\
\hline Unknown & 547 & 0.07 & 854 & 0.04 & 151 & 0.05 \\
\hline \multicolumn{7}{|l|}{ All ages } \\
\hline Localized & 1114 & 0.34 & 2371 & 0.22 & 1486 & 0.21 \\
\hline Nonlocalized & 2765 & 0.04 & 7769 & 0.02 & 3319 & 0.04 \\
\hline Unknown & 912 & 0.14 & 1702 & 0.05 & 242 & 0.08 \\
\hline
\end{tabular}

nonlocalized cancers, relative survival is poor in all countries, but, in general, Danish males and females do worse than the Norwegians and Finns. Even if those cases with stage and morphological subtype reported as unknown were distributed in such a way that the Finnish survival after localized disease would be lower, the effect is small and will not change the general observation that Danes do worse with respect to survival.

It is interesting to note the different temporal changes in relative 5-yr survival in the three countries [1] (figs. 1 and 2). Patient survival following lung cancer has improved over time in all countries, but the rate of improvement is negligible in Denmark. This signals that Denmark has possibly not been able to harvest advances in clinical practice (diagnosis and treatment), or that the other countries have introduced "something" which has not been introduced in Denmark. The healthcare systems are public and free in all these countries and the private healthcare sector negligible, so there should not be any financial consequences for individuals that might influence the survival. The authors are unaware, however, of any new development in therapy or diagnosis that has not been implemented in a similar fashion in each country.

Differences in stage at diagnosis seem to be the major reason for the inferior relative 5-yr survival of Danish lung cancer patients previously reported $[1,2]$. This was also found for cancers of the stomach, colon, rectum, breast and prostate, although all these in general have a better prognosis than lung cancer [20]. It is clear that more nonlocalized cases (and fewer localized) are diagnosed in Denmark than in the other two countries. No screening activities for lung cancer are carried out in the Nordic countries and, even if they were, these activities would not be expected to have any impact on lung cancer mortality. Since no special diagnostic activity is present in any of the Nordic countries, a systematic lead-time bias in Finland and Norway seems unlikely to be an explanation. It may be speculated that the population in Norway and Finland are more observant of lung cancer symptoms, and thus seek medical advice earlier. The fact that more localized cases are diagnosed in Norway and Finland suggests this. In addition, the impact of delays, other than patient delay, may influence the fate of the patients when lung cancer is present, since survival in general is rather poor. The importance of underlying risk factors should also be mentioned. Tobacco consumption was and still is much higher in Denmark than in the other countries. In $1985,51 \%$ of males and $43 \%$ of females in Denmark were smokers compared to 34 and $38 \%$, and 18 and $32 \%$, respectively, in Finland and Norway [21]. The female consumption and 
Table 4. - Number of cases and 5-yr relative survival (RSR) by morphological subtype, sex, and country

\begin{tabular}{|c|c|c|c|c|c|c|c|c|c|c|c|c|}
\hline & \multicolumn{6}{|c|}{ Localized } & \multicolumn{6}{|c|}{ Nonlocalized } \\
\hline & \multicolumn{2}{|c|}{ Finland } & \multicolumn{2}{|c|}{ Denmark } & \multicolumn{2}{|c|}{ Norway } & \multicolumn{2}{|c|}{ Finland } & \multicolumn{2}{|c|}{ Denmark } & \multicolumn{2}{|c|}{ Norway } \\
\hline & $\mathrm{n}$ & RSR & $\mathrm{n}$ & RSR & $\mathrm{n}$ & RSR & $\mathrm{n}$ & RSR & $\mathrm{n}$ & RSR & $\mathrm{n}$ & RSR \\
\hline \multicolumn{13}{|l|}{ Males } \\
\hline Small cell & 680 & 0.11 & 659 & 0.07 & 690 & 0.05 & 2946 & 0.02 & 3898 & 0.01 & 2180 & 0.02 \\
\hline Squamous cell & 3326 & 0.33 & 3167 & 0.24 & 2400 & 0.20 & 4215 & 0.05 & 5515 & 0.04 & 2861 & 0.07 \\
\hline Other & 1565 & 0.37 & 2059 & 0.20 & 1558 & 0.26 & 3771 & 0.03 & 6919 & 0.02 & 3783 & 0.04 \\
\hline Missing & 1537 & 0.07 & 527 & 0.07 & 615 & 0.04 & 3433 & 0.01 & 1412 & 0.01 & 913 & 0.01 \\
\hline \multicolumn{13}{|l|}{ Females } \\
\hline Small cell & 99 & 0.10 & 351 & 0.09 & 248 & 0.09 & 544 & 0.03 & 1780 & 0.03 & 801 & 0.03 \\
\hline Squamous cell & 272 & 0.30 & 695 & 0.22 & 361 & 0.23 & 424 & 0.06 & 1310 & 0.02 & 503 & 0.06 \\
\hline Other & 516 & 0.54 & 1143 & 0.32 & 703 & 0.29 & 1187 & 0.06 & 4127 & 0.02 & 1737 & 0.04 \\
\hline Missing & 227 & 0.10 & 182 & 0.06 & 174 & 0.03 & 610 & 0.01 & 550 & 0.03 & 278 & 0.02 \\
\hline
\end{tabular}

rise in lung cancer incidence is of particular concern. By using relative survival, noncancer smoking-related mortality has been to some extent adjusted for, however, a factor such as smoking, which is possibly even more prevalent among lung cancer patients than any other cannot be controlled for completely.

As always, it cannot be excluded that differences in registration practices may influence these findings, in particular the extent to which follow-back of cases first reported on a death certificate is carried out, and the recording of stage. The first was studied earlier in Denmark [22] and in the EUROCARE study [2], and found to be of little importance. Stage migration may also be ruled out [20], since Denmark had the lowest proportion of localized tumours but did not have a better stage-specific survival. Differences in morphology (with more unfavourable small cell carcinomas in Denmark, as seen in table 2) can be ruled out. In fact when tabulating data from the areas included in the EUROCARE study, it is evident that the proportion of small cell carcinomas is the same in Denmark as in countries with a superior survival.

In conclusion, the observed differences in patient survival following a diagnosis of lung cancer between Denmark, Norway, and Finland are real and exist for both males and females. The main factor influencing the lower 5 -yr relative survival in Denmark, that can be identified in this data, is the unfavourable stage distribution. Since survival differences are small within stage categories between the countries, differences in treatment choice or treatment efficacy subsequent to diagnosis are unlikely to explain these findings. However, differences in the point in the natural progression of the disease at which the initial diagnosis and initiation of treatment takes place seem to be the most likely explanation. There are two possible scenarios in which this could lead to lower patient survival in Denmark. The first is that the natural progression of the disease is similar in each of the Nordic countries, but diagnosis and initial treatment occur at a later stage in Denmark through either patient delay in seeking treatment following symptoms or physician delay in diagnosing the disease. The second scenario is that the natural progression of the disease is accelerated in Denmark for some patients, possibly due to a differing aetiology due to the higher prevalence of tobacco use. Although this is highly speculative, it is without doubt that lung cancer incidence and mortality in Denmark could be considerably reduced through primary prevention aimed at reducing the use of tobacco in parallel with effective diagnosis and treatment.

Acknowledgements. Statistician B.L. Thomsen, Danish Cancer Society is acknowledged for her helpful comment on this manuscript, and for suggesting a more comprehensive analysis of the data.

\section{References}

1. Engeland A, Haldorsen T, Tretli S, et al. Prediction of cancer mortality in the Nordic countries up to the years 2000 and 2010 on the basis of relative survival analysis. A collaborative study of the five Nordic cancer registries. APMIS 1995; 103: Suppl. 49, 1-163.

2. Berrino F, Sant M, Verdecchia A, Capocaccia R, Hakulinen T, Estève J, eds. Survival of Cancer Patients in Europe. The EUROCARE Study. IARC Scientific Publications No. 132. Lyon, International Agency for Research on Cancer, 1995.

3. Kessler LG. Lung and bronchus. In: Miller BA, Ries LAG, Hankey BF, Kosary CL, Edwards BK, eds. Cancer Statistics Review: 1973-1989. Washington, National Cancer Institute, NIH Publ. No. 92-2789, 1992.

4. Boyle P, Maisonneuve P. Lung cancer and tobacco smoking. Lung Cancer 1995; 12: 167-181.

5. Engeland A, Haldorsen T, Tretli S, et al. Prediction of cancer incidence in the Nordic countries up to the years 2000 and 2010. A collaborative study of the five Nordic cancer registries. APMIS 1993; 101: Suppl. 38, 1-124.

6. Fontana RS, Taylor WF. Screening for lung cancer: the Mayo Lung Project. In: Mizel M, Correa P, eds. Lung Cancer: Causes and Prevention. Dearfield Beach, FL, Verlag Chemie Int, 1984; pp. 161-174.

7. Kubik A, Parkin DM, Khlat M, Erban J, Polak J, Adamec M. Lack of benefit from semi-annual screening for cancer of the lung: follow-up report of a randomized controlled trial on a population of high-risk males in Czechoslovakia. Int J Cancer 1990; 45: 26-33.

8. Flehinger BJ, Kimmel M, Polyak T, Melamed MR. Screening for lung cancer. The Mayo Lung Project revisited. Cancer 1993; 72: 1573-1580.

9. Tulinius H, Storm HH, Pukkala E, Andersen A, Ericsson J. Cancer in the Nordic countries, 1981-86. A joint 
publication of the five Nordic Cancer Registries. APMIS 1992; 103: Suppl. 31, 1-194.

10. Dickman PW, Gibberd RW, Hakulinen T. Estimating potential savings in cancer deaths by eliminating regional and social class variation in cancer survival in the Nordic countries. J Epidemiol Community Health 1997; 51: 287298.

11. World Health Organization. ICD-O - International Classification of Diseases for Oncology. Geneva, World Health Organization, 1976.

12. Anonymous. Manual of Tumor Nomenclature and Coding (MOTNAC). American Cancer Society, 1951 and 1968.

13. Ederer F, Axtell LM, Cutler SJ. The relative survival rate: a statistical methodology. NCI Monogr 1961; 6: 101-121.

14. Henson DE, Ries LA. The relative survival rate. Cancer 1995; 76: 1687-1688.

15. Hakulinen T, Abeywickrama K. A computer program package for relative survival analysis. Comp Progr Biomed 1985; 19: 197-207.
16. European Network of Cancer Registries. EUROCIM User Manual, 2nd Edn. Lyon, International Agency for Research on Cancer, 1995.

17. Sant M, Gatta G, Capocaccia R, et al. Survival for lung cancer in Northern Italy. Cancer Causes Contr 1992; 3: 223-230.

18. Ries LA. Influence of extent of disease, histology and demographic factors on lung cancer survival in the SEER population-based data. Semin Surg Oncol 1994; 10: 21-30.

19. Travis WD, Travis LB, Devesa SS. Lung cancer. Cancer 1995; 75: 191-202.

20. Engeland A, Haldorsen T, Dickman PW, et al. Relative survival of cancer patients. A comparison between Denmark and the other Nordic countries. Acta Oncol 1998; 37: 49-59.

21. Dreyer L, Winther JF, Pukkala E, Andersen A. Tobacco smoking. APMIS 1997; 105: Suppl. 76, 9-47.

22. Carstensen B. Material and methods. In: Carstensen B, Storm HH, Schou G, eds. Survival of Danish Cancer Patients 1943-1987. APMIS 1993; 101: Suppl. 33, 3-8. 